\title{
DESENVOLVIMENTO DE JOGOS DIDÁTICOS COMO FERRAMENTA DE ENSINO NA DISCIPLINA DE GEOLOGIA APLICADA A ENGENHARIA
}

\author{
Mariana Alher Fernandes - marianaalher@utfpr.edu.br \\ Universidade Tecnológica Federal do Paraná, Câmpus Apucarana \\ Rua: Marcílio Dias, 635 \\ CEP: 86812-460 - Apucarana - Paraná
}

\begin{abstract}
Resumo: A utilização de jogos didáticos para a prática de ensino-aprendizagem busca contribuir na evolução do conhecimento e no raciocínio do aluno. Dessa maneira, os jogos didáticos funcionam como poderosas ferramentas de ensino e de contextualização para um dado conteúdo. Nesse sentido, o objetivo desse trabalho visa relatar o desenvolvimento de jogos didáticos por alunos do $2^{\circ}$ Semestre de 2019 que cursaram a disciplina de Geologia Aplicada a Engenharia do curso de Engenharia Civil da Universidade Tecnológica Federal do Paraná, Câmpus Apucarana. Os alunos foram divididos em grupos de 4 a 5 integrantes, cada grupo tendo um tema diferente de trabalho. A proposta dos temas dos jogos didáticos estava baseada na ementa da disciplina sendo desenvolvidos no modelo de jogos de tabuleiro ou jogos de cartas. Todos os jogos foram expostos ao público no final do semestre num evento denominado como I Mostra de Geologia Aplicada a Engenharia. Os alunos se mostraram animados e estimulados com os jogos apesar da timidez de muitos deles durante a exposição dos trabalhos. Devido a sistemática simples de alguns desses jogos, é possível que pessoas leigas possam utilizá-los, não necessitando de um conhecimento prévio na área de Geologia. Pode-se dizer que foi uma experiência positiva não apenas aos alunos, mas também para a docente da disciplina.
\end{abstract}

Palavras-chave: Ensino. Aprendizagem ativa. Jogo didático. Engenharia civil.

\section{INTRODUÇÃO}

As metodologias ativas de ensino-aprendizagem correspondem às formas inovadoras de educação, em que o professor tem o papel de orientador e o aluno torna-se o protagonista no seu processo educacional, participando ativamente da construção do seu próprio saber. Dentre as práticas de ensino-aprendizagem mais comuns em metodologias ativas destacam-se a Aprendizagem Baseada em Projeto (ou Project-Based Learning - PBL), Aprendizagem entre Pares e Times (ou Peer Instruction - PI e Team-Based Learning - TBL), Aprendizagem Baseada em Problemas (ou Problems-Based Learning - PBL), Sala de aula invertida (ou Flipped Classroom - FC) e ainda a Aprendizagem Baseada em Jogos (ou Game-Based Learning - GBL).

A palavra Gamificação é um termo que provém do inglês (gamificacion) e que tem sido recentemente muito difundida e empregada na área educacional. Dessa maneira, da perspectiva educacional, o uso de gamificação consiste na aplicação de elementos advindos do design de jogos tendo como finalidade motivar a aprendizagem do aluno e estimular o desenvolvimento de suas competências socioemocionais. A incorporação de atividades lúcidas, como jogos 
didáticos, possibilita que o professor torne a disciplina mais interessante e atraente ao acadêmico podendo auxiliar na estruturação dos conceitos, colaborar na evolução da criatividade e fortalecer o conhecimento (FREITAS FILHO E SCHRÖTER, 2018). Portanto, pode-se dizer que o jogo didático ou jogo pedagógico corresponde ao material produzido com a finalidade de atuar no progresso e no desenvolvimento da aprendizagem dos alunos além de incentivar a formação de um novo conhecimento (PEREIRA e RIBEIRO, 2015; CAMPOS et al., 2002).

Dentro desse contexto, é possível constatar diversos relatos em publicações científicas discorrendo sobre o desenvolvimento e o emprego dessa metodologia de aprendizagem por docentes atuantes em diferentes áreas do curso de Engenharia Civil. Dessa maneira, destacamse trabalhos relatando o uso de plataformas online de jogos educacionais como Kahoot e Socrative (GONTIJO et al., 2016; MOTA et al., 2018; PASSOS, 2018; BACELAR et al., 2019; MOTA et al., 2019), o desenvolvimento e/ou aplicação de jogos (TEIXEIRA, 2009; BERNARDINIS et al., 2017; MINIKOWSKI, 2018; RIBEIRO et al., 2019; OLIVEIRA et al., 2019; LIMA e LOPES, 2020)

Nesse sentido, o presente trabalho visa contribuir no processo de ensino aprendizagem de engenharia com a utilização de jogos didáticos, apresentando um relato do procedimento metodológico adotado com os alunos do curso de Engenharia Civil matriculados no $2^{\circ}$ Semestre do ano de 2019 da disciplina de Geologia Aplicada a Engenharia da Universidade Tecnológica Federal do Paraná do Paraná (UTFPR), Câmpus Apucarana, tendo como finalidade a elaboração e o desenvolvimento de jogos didáticos na área desta disciplina.

\section{METODOLOGIA}

A proposta deste método de ensino-aprendizagem foi aplicada aos alunos da disciplina de Geologia Aplicada a Engenharia da Universidade Tecnológica Federal do Paraná, Câmpus Apucarana (UTFPR-AP), no segundo semestre do ano de 2019. Atualmente, a disciplina no curso de Engenharia Civil possui uma carga horária de 60 horas aula, tendo 30 horas aula de aula teórica e 30 horas aula de aula prática. No caso da aula prática, a disciplina é dividida em turma A e turma B, cada turma composta por aproximadamente 22 alunos.

\subsection{Temas e tipos de jogos de jogos didáticos}

Os alunos foram separados em grupo por meio de sorteio, desse modo possibilitando saírem da zona de conforto assim como desenvolverem novas habilidades pessoais. Cada grupo era composto por 4 ou 5 cinco integrantes, estando todos eles obrigatoriamente matriculados na mesma turma.

Na matriz do curricular do curso de Engenharia Civil da UTFPR Câmpus Apucarana, a disciplina de Geologia Aplicada a Engenharia contempla o núcleo de conteúdo profissionalizante, é ministrada no quarto período do curso e não possui pré-requisito. A ementa dessa disciplina aborda sobre Importância e conceitos fundamentais, minerais, rochas magmáticas, rochas sedimentares, rochas metamórficas, intemperismo, utilização de solos e rochas na Engenharia Civil, formação dos solos, as modificações superficiais, estudo do subsolo, água superficial e subsuperficial, água subterrânea, Geologia de taludes, Geologia em obras de engenharia e Geologia de engenharia aplicada ao meio ambiente.

Todos os temas de trabalho foram sugeridos na primeira quinzena de aula e estavam relacionados com a ementa da disciplina, não havendo objetivos de jogos repetidos. Dessa maneira, os temas desses trabalhos foram sorteados durante a aula teórica e na presença de todos os alunos das duas turmas, a fim de evitar disputas entre os grupos por determinados assuntos. Além disso, o tipo de jogo didático a ser desenvolvido ao longo do semestre letivo 
estava acompanhado do tema de trabalho, como mostra o Quadro 1. Observa-se neste quadro os temas Minerais 1 e Minerais 2, em que a diferença entre esses jogos consiste na configuração das cartas, em Minerais 1 o grupo fará o levantamento de 5 características comum a todos minerais enquanto que em Minerais 2 o grupo deverá desenvolver cartas para formar pares (podendo também ser utilizado como jogo da memória).

Quadro 1 - Tema de trabalho e tipo de jogo didático sugerido.

\begin{tabular}{|c|c|c|}
\hline $\mathrm{N}^{\mathbf{o}}$ Tema & Tema de Trabalho & Tipo de Jogo Didático \\
\hline 1 & Minerais 1 & Jogo de cartas \\
\hline 2 & Minerais 2 & Jogo de cartas \\
\hline 3 & Ciclo das Rochas & Jogo de tabuleiro \\
\hline 4 & Rochas Ígneas & Jogo de cartas \\
\hline 5 & Rochas Sedimentares & Jogo de tabuleiro \\
\hline 6 & Rochas Metamórficas & Jogo de tabuleiro \\
\hline 7 & Formação dos Solos & Jogo de tabuleiro \\
\hline 8 & Águas Superficiais & Jogo de cartas \\
\hline 9 & Edifícios do Mundo & Jogo de cartas \\
\hline 10 & Barragens Brasileiras & Jogo de cartas \\
\hline
\end{tabular}

Fonte: Próprio Autor (2020)

\subsection{Desenvolvimento dos jogos didáticos}

O desenvolvimento dos jogos se deu ao longo do semestre letivo, em que os alunos tiveram que apresentar obrigatoriamente um documento relatando a evolução do mesmo além de ter um tempo (aproximadamente 20 minutos) para mostrar o andamento do trabalho. Esta prática adotada foi denominada de acompanhamento, totalizando três acompanhamentos no decorrer do semestre. Portanto, cada grupo tinha a oportunidade de apresentar seu desempenho e a evolução do trabalho à docente no intervalo de um mês além de poderem sanar possíveis dúvidas ou até mesmo apontarem dificuldades no desenvolvimento dos seus respectivos temas.

De maneira geral, tem-se alguns objetivos específicos na realização dos acompanhamentos tais como auxiliar o aluno no desenvolvimento desse trabalho ao longo do semestre, dar oportunidade para o aluno elaborar um trabalho de qualidade e dedicar seu tempo em pequenas doses, evitar que o aluno acumule trabalho para o final do semestre, prejudicando na qualidade e conteúdo desse trabalho. Portanto, com a finalidade de atingir esses objetivos, foram realizados esses três acompanhamentos, em que pretendia com que cada grupo avançasse no desenvolvimento dos jogos didáticos.

Desse modo, o primeiro acompanhamento tinha como ideia central desenvolver a criação do jogo, isto é, imaginar o esboço do tabuleiro ou das cartas, como seriam elaboradas as regras do jogo assim como os tipos de pergunta e resposta, o grau de dificuldade do jogo. Já a meta do segundo acompanhamento era colocar em prática as ideias levantadas no acompanhamento anterior, ou seja, caso o jogo fosse de tabuleiro os alunos deveriam preparar o tabuleiro propriamente dito com a quantidade de "casas" a serem percorridas (distribuindo "casa" bônus - com pergunta e resposta - e "casa" neutra), realizar teste com o quiz pretendido e verificar se as regras do jogo estavam compatíveis com a ideia inicial. E para finalizar, o terceiro acompanhamento seria para sanar dúvidas e finalizar o trabalho, com a elaboração da arte final do tabuleiro ou das cartas, término das questões do quiz bem como as regras do jogo.

A entrega do jogo didático foi realizada no horário da aula prática, em que os alunos fizeram uma exposição desses jogos num local próximo ao Restaurante Universitário do Câmpus Apucarana da UTFPR, sendo a exposição denominada de I Mostra de Geologia 
Aplicada a Engenharia. Neste local tinha disponível uma mesa para cada grupo e diversas cadeiras, de forma com que outros alunos pudessem jogar, aprender e se interessar pelo conteúdo de Geologia. Além da exposição dos jogos, os alunos também elaboraram um artigo científico descrevendo o jogo didático.

\subsection{Avaliação dos jogos didáticos}

Os participantes da exposição (exceto os integrantes do próprio grupo) puderam avaliar os jogos didáticos que manusearam e jogaram durante a realização da I Mostra de Geologia de Aplicada a Engenharia. Para isso, a docente elaborou previamente uma ficha de avaliação e distribuiu 20 unidades para cada grupo. Essa ficha de avaliação deveria ser preenchida por cada participante, o qual deveria responder de que curso era docente ou discente assim como deveria atribuir uma nota numa escala de 5 a 10 para itens pertinentes ao jogo, sendo 5 a nota mínima e 10 a nota máxima. O Quadro 2 apresenta o modelo dessa ficha de avaliação.

Quadro 2 - Ficha de avaliação distribuída aos participantes da exposição.

\begin{tabular}{|c|c|c|c|c|c|c|c|}
\hline \multicolumn{8}{|c|}{ Docente - curso de Engenharia Civil } \\
\hline \multicolumn{8}{|c|}{ Docente - de outro curso. Qual? } \\
\hline \multicolumn{8}{|c|}{ Discente - curso de Engenharia Civil } \\
\hline \multicolumn{8}{|c|}{ Discente - de outro curso. Qual? } \\
\hline \multirow{2}{*}{$\mathrm{N}^{\mathrm{o}}$} & \multirow{2}{*}{ Item avaliado } & \multicolumn{6}{|c|}{ Nota atribuída } \\
\hline & & 5 & 6 & 7 & 8 & 9 & 10 \\
\hline 1 & O jogo é dinâmico? & & & & & & \\
\hline 2 & As regras do jogo são claras? & & & & & & \\
\hline 3 & O objetivo do jogo foi atingido? & & & & & & \\
\hline 4 & O jogo é estimulante e criativo? & & & & & & \\
\hline 5 & O jogo torna o conteúdo da disciplina mais atrativo? & & & & & & \\
\hline 6 & $\begin{array}{l}\text { O que achou do tempo do jogo (considerando início e } \\
\text { término da partida)? }\end{array}$ & & & & & & \\
\hline 7 & O que você achou do visual/ilustração do jogo? & & & & & & \\
\hline 8 & Você aprendeu algo novo com o conteúdo do jogo? & & & & & & \\
\hline 9 & $\begin{array}{l}\text { Quanto a atividade ajudou na compreensão do conteúdo do } \\
\text { jogo? }\end{array}$ & & & & & & \\
\hline 10 & Gostaria de utilizar atividades como esse durante as aulas? & & & & & & \\
\hline 11 & A atividade estava fácil de ser utilizada? & & & & & & \\
\hline 12 & A atividade estava didática? & & & & & & \\
\hline
\end{tabular}

Fonte: Próprio Autor (2020)

\section{RESULTADOS E DISCUSSÕES}

A proposta inicial dos jogos de rochas metamórficas e rochas sedimentares foi alterada durante os acompanhamentos dos alunos com a docente, uma vez que estes grupos estavam com dificuldades em encontrar informações quantitativas pertinentes ao assunto, tais como características das rochas, para elaboração das cartas. Dessa maneira, os dois jogos foram desenvolvidos no formato de jogo de tabuleiro.

Os jogos de tabuleiro foram confeccionados a partir de um percurso dividido em diversas "casas" tendo a opção de atalho nesse percurso em alguns desses jogos. Muitas dessas "casas" eram neutras, ou seja, correspondiam apenas a casas de passagens enquanto que outras "casas" continha algum tipo de simbologia, como ponto de interrogação ou cores do tabuleiro, para 
indicar que haveria perguntas. Alguns dos jogos utilizaram perguntas com diferentes graus de dificuldade (baixo, médio e alto), como o jogo de tabuleiro de rochas sedimentares (Figura 1a) enquanto outros jogos empregaram um único grau de dificuldade de perguntas, como o jogo de tabuleiro de formação dos solos (Figura 1b). Destaca-se que nesses jogos de tabuleiro era exigido um conhecimento prévio acerca do assunto de Geologia de forma com que o estudante pudesse responder aos questionamentos referentes às perguntas mencionadas anteriormente. Dessa maneira, esses jogos só podem ser utilizados com alunos da disciplina de Geologia Aplicada a Engenharia após terem passado pelo processo de aprendizagem do conteúdo relativo ao jogo.

Figura 1 - Jogo de tabuleiro de (a) rochas sedimentares (b) formação dos solos.

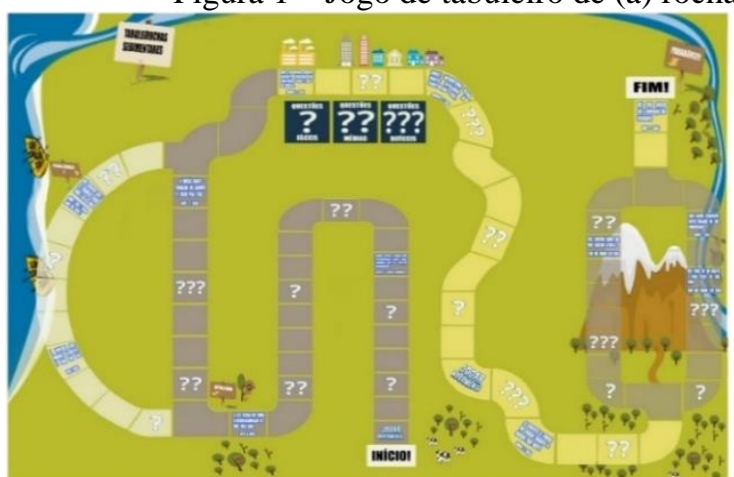

(a)

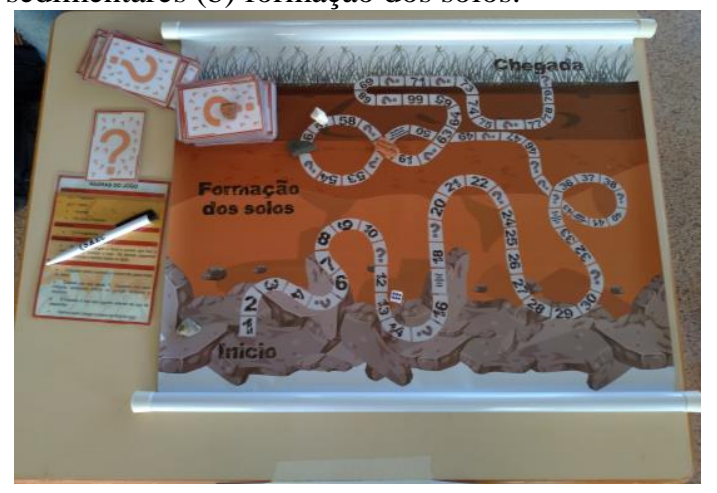

(b)

Fonte: Próprio Autor (2019)

Além dos jogos de tabuleiros também foram confeccionados jogos de cartas, em que os grupos de cada tema produziram jogos de 32 cartas, todas elas possuindo quatro ou cinco características semelhantes. Também foram utilizadas imagens para ilustrar o item objeto de estudo acompanhado do seu nome ou outro aspecto relevante para identificá-las. Ressalta-se que esses jogos de cartas podem ser utilizados por alunos de qualquer período ou pessoas leigas no assunto abordado, uma vez que não necessita de conhecimento prévio de Geologia. Também é importante salientar que a utilização por outros alunos ou até mesmo outro público alvo pode despertar o interesse no conteúdo abordado e estimular o estudo do assunto. Portanto, estes jogos podem ser utilizados com alunos do Ensino Médio e Ensino Fundamental na disciplina de Geografia, por exemplo. A Figura 2 ilustra um exemplo de carta confeccionada na temática de barragens brasileiras e de minerais (tema de trabalho denominado como Minerais 2).

Figura 2 - Jogo de cartas de (a) barragens brasileiras (b) minerais.

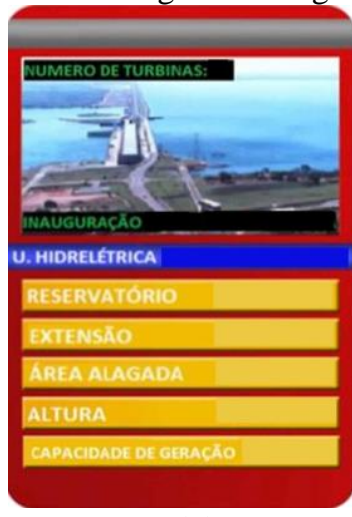

(a)
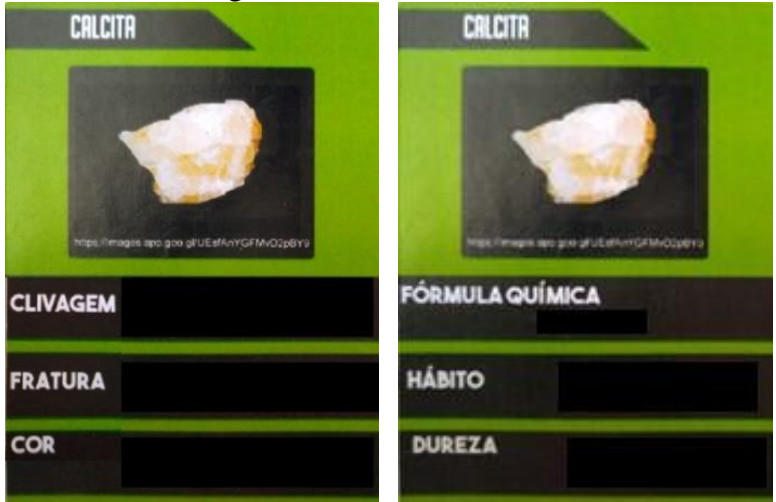

(b)

Fonte: Próprio Autor (2019) 
A Figura 3 apresenta um momento da exposição das Turmas A e B, em que é possível visualizar nas imagens os alunos manuseando os jogos e interagindo uns com os outros. A exposição foi realizada no horário da aula prática, tendo a duração de 1 hora e 40 minutos para cada turma. De acordo com os comentários mencionados pelos participantes e pelos próprios alunos da disciplina à docente, percebe-se que o objetivo com a confecção e o desenvolvimento desses jogos foram atingidos, uma vez que houve a aprovação desses jogos tendo apenas recebido algumas recomendações para a maioria dos jogos de carta devida à duração da partida, sendo necessário rever as regras desses jogos. Em geral, a maioria dos alunos ficaram tímidos no início da exposição, porém aos poucos eles foram deixando de lado a timidez e demonstrando interesse pelos jogos. Observou-se que o ambiente ficou movimentado e descontraído no final da exposição e os participantes, inclusive os próprios alunos, estavam animados e estimulados com os jogos.

Figura 3 - Participantes durante a exposição dos jogos (a) Turma A (b) Turma B.

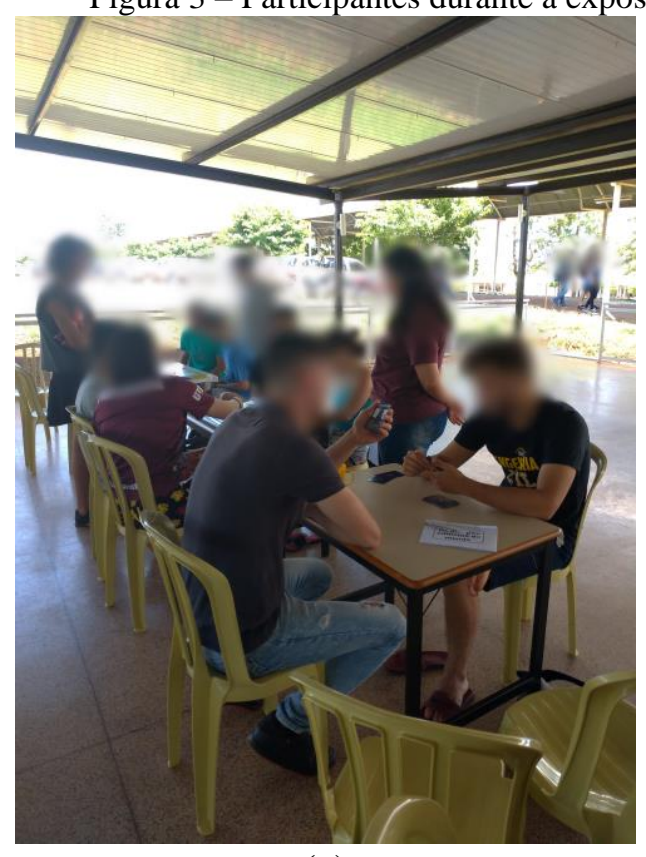

(a)

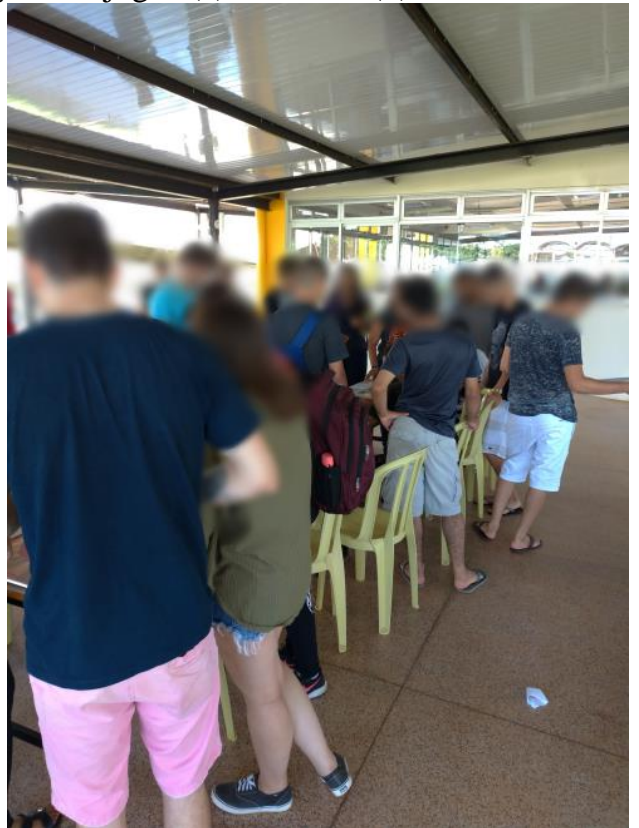

(b)

Fonte: Próprio Autor (2019)

Já referente a avaliação dos trabalhos, a Figura 4 reúne o levantamento do universo de participantes distribuídos em função da numeração do tema de trabalho apresentado no Quadro 1. Durante a exposição foram respondidas 171 fichas de avaliação totalizando 6 por docentes do curso de Engenharia Civil, 1 por docente do curso de Química, 100 por discentes do curso de Engenharia Civil, 9 por discentes de outros cursos (como Engenharia Química, Engenharia Têxtil, Química) e 55 acabaram por não assinalar nenhuma opção. Tendo a finalidade de comparar as notas entre os grupos, optou-se em determinar a média aritmética de cada item avaliado, conforme representado na Tabela 1, resultando nos itens 3 (O objetivo do jogo foi atingido?) e 5 (O jogo torna o conteúdo da disciplina mais atrativo?) como os melhores avaliados enquanto que os itens 6 (O que achou do tempo do jogo - considerando início e término da partida?) e 7 (O que você achou do visual/ilustração do jogo?) como os piores avaliados. Dessa maneira, as Figuras 5 e 6 ilustram a média aritmética para os melhores e piores itens avaliados, respectivamente, em função da numeração do tema de trabalho apresentado no Quadro 1. 
$2020 \begin{aligned} & \text { XLVIII Congresso Brasileiro } \\ & \text { de Educaçäo em Engenharia } \\ & \text { ellI Simpósio Internacional } \\ & \text { de Educaçäo em Engenharia } \\ & \text { da ABENGE }\end{aligned}$

"Os desafios para formar hoje o engenheiro do amanhã"
$\mathrm{Ol} \mathrm{a} \mathrm{O3}$ de dezembro Evento On-line

Figura 4 - Levantamento do universo dos participantes.

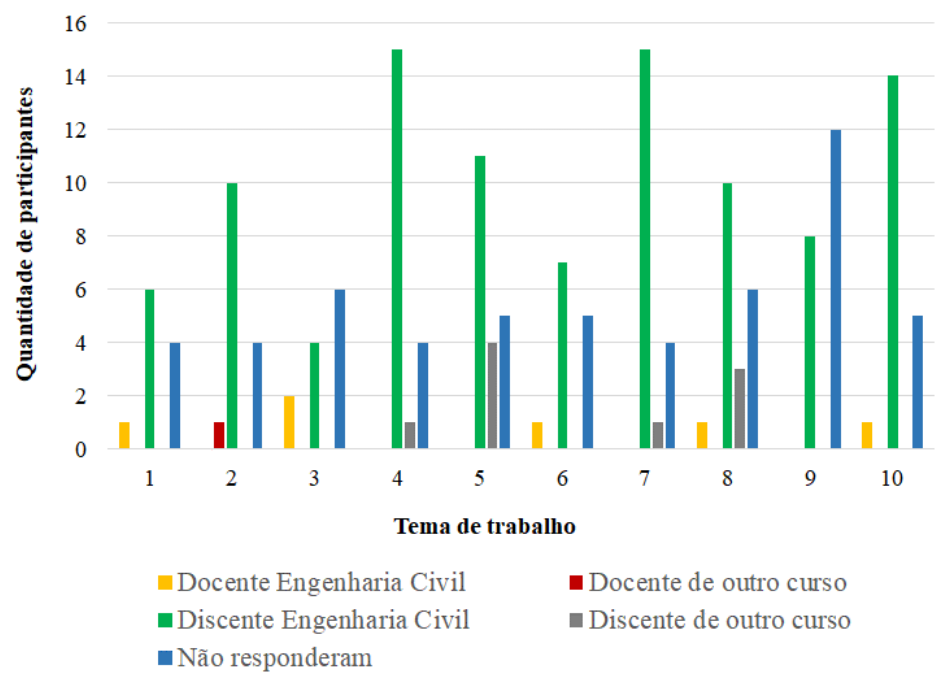

Fonte: Próprio Autor (2020)

Tabela 3 - Média aritmética dos itens avaliados.

\begin{tabular}{c|c|c}
\hline $\mathrm{N}^{\mathrm{O}}$ & Item Avaliado & Média Aritmética \\
\hline 1 & O jogo é dinâmico? & 9,94 \\
\hline 2 & As regras do jogo são claras? & 9,96 \\
\hline 3 & O objetivo do jogo foi atingido? & 9,98 \\
\hline 4 & O jogo é estimulante e criativo? & 9,93 \\
\hline 5 & O jogo torna o conteúdo da disciplina mais atrativo? & 9,97 \\
\hline 6 & O que achou do tempo do jogo (considerando início e término da & 9,83 \\
\hline 7 & partida)? & 9,88 \\
\hline 8 & O que você achou do visual/ilustração do jogo? & 9,94 \\
\hline 9 & Qocê aprendeu algo novo com o conteúdo do jogo? & 9,93 \\
\hline 10 & Gostaria de utilizar atividades como esse durante as aulas? & 9,94 \\
\hline 11 & A atividade estava fácil de ser utilizada? & 9,93 \\
\hline 12 & A atividade estava didática? & 9,96 \\
\hline
\end{tabular}

Fonte: Próprio Autor (2020)

Figura 5 - Média aritmética para os melhores itens avaliados.

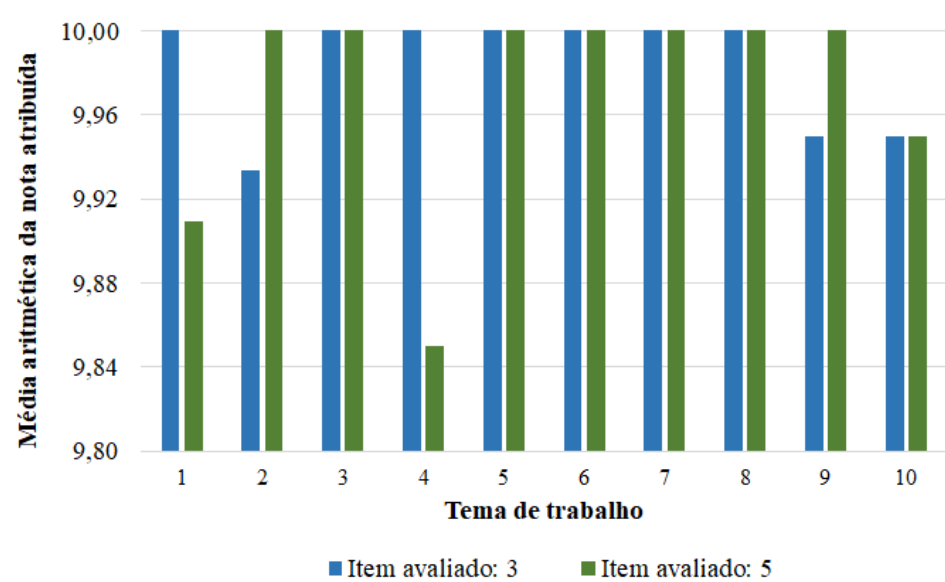

Fonte: Próprio Autor (2020) 


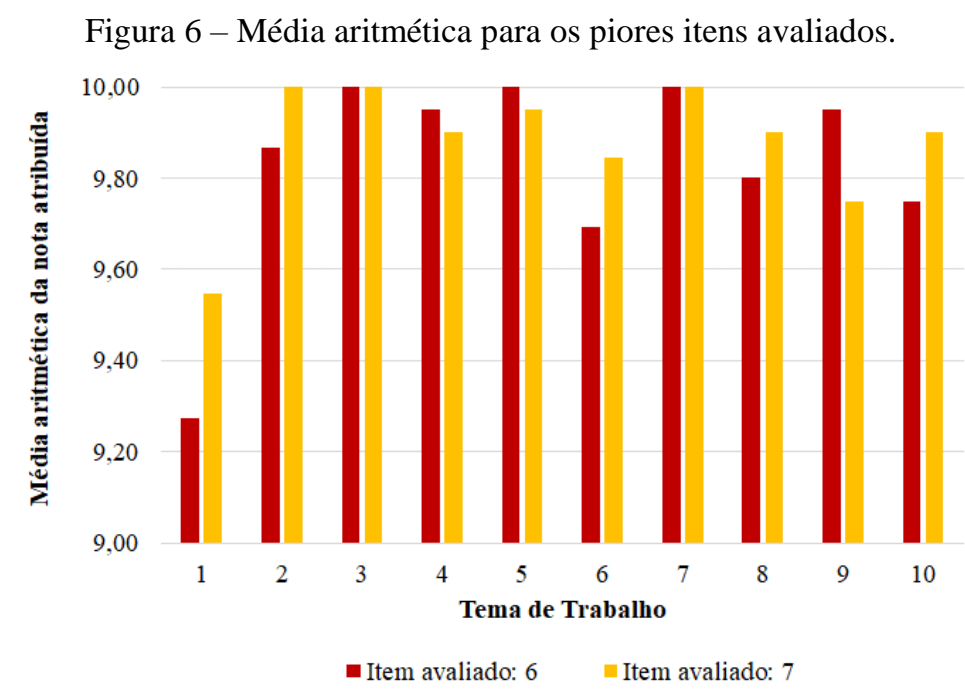

Fonte: Próprio Autor (2020)

Observa-se na Figura 4 que muitos participantes não assinalaram se eram docentes ou discentes, dificultando conhecer o universo do público que efetivamente realizou a avaliação do jogo. Logo, as fichas de avaliações sem identificação dos participantes resultaram em 55, as quais representam $32,2 \%$ em relação ao total de fichas, mostrando ser um número considerável em função do universo de 171 participantes.

Na Figura 5, que ilustra a nota dos melhores itens avaliados, nota-se que os trabalhos que obtiveram menores notas foram Minerais 2 (Tema $\left.n^{\circ} 2\right)$ para o item 3 e Rochas Ígneas (Tema $\mathrm{n}^{\circ}$ 4) para o item 5. Já na Figura 6, que apresenta a nota dos piores itens avaliados, observa-se que um único trabalho obteve menor nota nos itens 6 e 7, sendo este o trabalho de Minerais 1 $\left(\right.$ Tema $\left.n^{\circ} 1\right)$.

\section{CONSIDERAÇÕES FINAIS}

A proposta da atividade foi voltada para o desenvolvimento de jogos didáticos na temática de Geologia aplicada aos alunos da disciplina de Geologia Aplicada de Engenharia do curso de Engenharia Civil da Universidade Tecnológica Federal do Paraná, Câmpus Apucarana. A confecção, e posterior utilização dos jogos, não são direcionadas apenas para facilitar o aprendizado dos alunos da própria disciplina ou do curso de Engenharia Civil mas também com a intenção de explorar a interdisciplinaridade de determinados conteúdos com os alunos e de despertar o interesse de pessoas leigas no assunto. Além disso, é possível utilizar alguns desses jogos com alunos do Ensino Fundamental e Ensino Médio, podendo inclusive ser elaborado projeto de extensão envolvendo a comunidade local.

De maneira a dar continuidade com essa proposta, pretende-se aperfeiçoar os jogos produzidos seja a partir da modificação no design do tabuleiro e/ou cartas, reformulação de perguntas ou até mesmo na alteração das regras do jogo. A docente também pretende continuar no desenvolvimento de propostas na temática de jogos didáticos na disciplina de Geologia Aplicada a Engenharia e em outras disciplinas ministradas a partir do cadastro de projeto de ensino na sua Instituição de Ensino. Devido aos resultados satisfatórios com as turmas do semestre anterior atualmente está em andamento o uso da mesma proposta com as Turmas A e B do $1^{\circ}$ Semestre de 2020 da disciplina Geologia Aplicada a Engenharia na UTFPR Câmpus Apucarana, sendo empregados na sala de aula alguns dos jogos produzidos e apresentados no presente trabalho. 


\section{Agradecimentos}

A autora do trabalho agradece e parabeniza os alunos da disciplina de Geologia Aplicada a Engenharia do $2^{\circ}$ Semestre do ano de 2019 da UTFPR, Câmpus Apucarana, pela dedicação, compromisso e empenho no desenvolvimento dos jogos didáticos.

\section{REFERENCIAS}

BACELAR, Felipe A.; RIOS, Margarida, F.; CARVALHO, Tereza M. X. B. de. Proposta de ensino aprendizagem a ser aplicada em disciplinas de Engenharia Civil na Universidade de Fortaleza. Revista de Estudos e Pesquisas sobre Ensino Tecnológico, Manaus, v.5, n.10, p. 403-413, 2019.

BERNARDINIS, Márcia de A. P.; SUGUNOSHITA, Maria C.; COSTA, Rodolfo A. da; PINTO, Marcelo S. N. Análise da aplicação da gamificação e aprendizagem baseada em problemas na disciplina de sistemas de transportes do curso de Engenharia Civil da Univeridade Federal do Paraná nos anos de 2013, 2014 e 2016. Congresso Internacional de Ambientes Hipermídia para Aprendizagem, v.3, n.11, p. 84-92, 2017.

CAMPOS, L. M. L.; BORTOLOTO, T. M.; FELÍCIO, A. K. C. A produção de jogos didáticos para o ensino de ciências e biologia: uma proposta para favorecer a aprendizagem. Disponível

em:

http://unesp.br/prograd/PDFNE2002/aproducaodejogos.pdf/aproducaodejogos.pdf. Acesso em: 22 maio 2020.

FREITAS FILHO, Fernando L.; SCHRÖTER, Brigite A. F. O uso de jogos didáticos no processo de ensino e aprendizagem no ensino superior: jogo da inovação. In: VIII Congresso Internacional de Conocimiento e Innovación, 2018, Guadalajara. Anais. Guadalajara, 2018.

GONTIJO, Gabriele M.; ARAÚJO, Ana C. A.; RODRIGUES, Otávia, M. S. Análise de utilização de jogos como ferramenta de ensino em turmas de engenharia. In: XLIV Congresso Brasileiro de Educação em Engenharia, 2016, Natal. Anais. Natal, 2016.

LIMA, Jessica H. de; LOPES, Danielly A. Uso de jogo educacional na Engenharia Civil: tornando o dimensionamento de pavimentos divertido como o "Jogo Dimensione". Revista Internacional de Educação Superior, [S.1], v.7, p. 1-13, 2020.

MINIKOWSKI, Bruna; KELLER, Susie C.; GARCIA, Tatiana R.; SACCHELLI, Carlos M.; BONETTE, Jonathan C. C. Ferramenta de aprendizagem de conceitos de Engenharia Civil e áreas afins: Jogo Superinfra. In: XLVI Congresso Brasileiro de Educação em Engenharia, 2018, Salvador. Anais. Salvador, 2018.

MOTA, Bruno C.; OLIVEIRA, Francisco H. L. de; BARROSO, Suelly H. de A. A ferramenta Kahoot aplicada à disciplina de projeto e construção de superestrutura viária. In: XLVI Congresso Brasileiro de Educação em Engenharia, 2018, Salvador. Anais. Salvador, 2018.

MOTA, Bruno C.; SILVA, Webert B. C. da; OLIVEIRA, Francisco H. L. de; BARROSO, Suelly H. de A. A utilização da aprendizagem baseada em jogos para auxiliar o processo de 
ensino-aprendizagem na área de infraestrutura de transportes. In: XLVII Congresso Brasileiro de Educação em Engenharia, 2019, Fortaleza. Anais. Fortaleza, 2019.

OLIVEIRA, Letícia S. de; BARROSO, Suelly H. de A.; SOARES, Jorge B. A utilização de jogos como ferramenta de aprendizagem do ensino da disciplina de materiais betuminosos.

Revista Transportes, [S.1], v.17, n.4, p. 51-62, 2019.

PASSOS, Julio C. F. dos. Análise do uso das metodologias ativas de aprendizagem: estudo de caso no ensino de logística e transportes. 2018. 130 f. Dissertação (Mestrado) - Faculdade de Engenharia Civil, Arquitetura e Urbanismo, Universidade Estadual de Campinas, Campinas, 2018.

PEREIRA, Josiele A.; RIBEIRO, Juliana Z. O lúdico como recurso didático no ensino de ciências biológicas para alunos da educação de jovens e adultos. Revista Eletrônica de Educação da Faculdade Araguaia, [S.1], v.7, n.7, p. 381-386, 2015.

RIBEIRO, Iracira J. da C.; SILVA, Jeferson J. S. da; SILVA, José E. da R.; SILVA, Tamires N. da; SILVA, Tiago J. da. CREA em construção: uma proposta de jogo educativo. In: XLVII Congresso Brasileiro de Educação em Engenharia, 2019, Fortaleza. Anais. Fortaleza, 2019.

TEIXEIRA, Micaela da S. Compilação de jogos didáticos para ensino de gerenciamento da produção na construção civil - uma abordagem a partir dos conceitos lean. 2009. $74 \mathrm{f}$. Monografia (Trabalho de Conclusão de Curso) - Curso de Engenharia Civil, Universidade Federal do Ceará, Fortaleza, 2009.

\title{
DEVELOPMENT OF DIDATIC GAMES AS A TOOL OF LEARNING IN THE DISCIPLINE OF GEOLOGY APPLIED IN ENGINEERING
}

\begin{abstract}
The application of educational games for teaching-learning practice seeks to contribute to the evolution of knowledge and student logic. Thus, didactic games function as powerful teaching and contextualization tools for certain content. In this sense, the aim of this work was to report how proceeded the development of didactic games by undergraduate of 2 nd Semester of 2019 that attended the discipline of Geology Applied to Engineering the course of the Civil Engineering at the Federal University of Technology-Paraná, Campuses Apucarana. The alumnus were divided into groups of 4 to 5 members, each group having a different work theme. The themes of the didactic games were based on the course menu being developed in the model of board games or card games. All games were exposed to the public at the end of the semester in an event called the 1st Exhibition of Geology Applied to Engineering. The students were excited and encouraged by the games despite the shyness of many of them during the exhibition of the works. Due to the simple systematic of some of these games, it is possible that lay people can use them, not being necessary a previous knowledge in the area of Geology. It can be said that it was a positive experience not only for the undergraduate, but also for the teacher of the discipline.
\end{abstract}

Keywords: teaching, active learning, didactic game, civil engineering. 